\title{
O ENSINO DE SOLOS COMO PRÁTICA DE EDUCAÇÃO AMBIENTAL NA ESCOLA MUNICIPAL DE ENSINO FUNDAMENTAL SANTO ISIDORO - GAURAMA/RS
}

\author{
Cleusa Fátima Sandalowski
}

\section{RESUMO}

Esta pesquisa teve por objetivo analisar se o ensino de solos pode contribuir para a prática da Educação Ambiental na Escola Municipal de Ensino Fundamental Santo Isidoro - Gaurama/RS. Foram analisados oito livros didáticos com o intuito de verificar o enfoque dado pelos autores a temática solo, bem como observadas as atividades desenvolvidas pelo professor e alunos da $8^{a}$ Série - Turma 82, no "Projeto do Viveiro", nas aulas de Técnicas Agrícolas, relacionando-as com o ensino e conhecimento do solo e a prática da Educação Ambiental. Por meio da análise dos dados e da experiência vivenciada nas aulas práticas de Técnicas Agrícolas pode-se verificar que a temática solo não é abordada em todos os livros didáticos de $5 \underline{a}$ a 8$^{a}$ Séries do Ensino Fundamental utilizados na Escola Municipal de Ensino Fundamental Santo Isidoro, no entanto o conhecimento desse tema ocorre de forma mais contundente nas aulas práticas da disciplina de Técnicas Agrícolas, que tem como "sala de aula" o viveiro da escola. Deste modo, o conhecimento proveniente do estudo do solo gera a prática da Educação Ambiental, uma vez que visa à formação de um aluno consciente da responsabilidade que tem para com o meio no qual vive.

Palavras-chave: ensino de solos, prática, educação ambiental.

\section{INTRODUÇÃO}

De acordo com Lepsch (2002, p. 8): “há milhares de anos o solo é responsável pelo fornecimento de materiais, sejam eles alimentícios como vegetais e animais, ou para a confecção de objetos e pigmentos para pinturas. Inicialmente, porém, o solo era visto como algo que se confundia com o restante da crosta terrestre sendo pensado como fixo e imutável".

Todavia, com o advento da industrialização tornou-se claro de que a apropriação do homem sobre os recursos naturais sem a preocupação com o seu futuro resultou em uma crise ambiental. Nesse sentido, a partir da década de 1960, começaram a surgir pelo mundo, movimentos de defesa e preocupação com o meio ambiente, os quais formularam propostas de uma Educação Ambiental para a preservação do ambiente.

A primeira definição internacional sobre o conceito de Educação Ambiental foi feita pela International Union for the Conservation of Nature (IUCN) em 1971, que ressaltou os aspectos ecológicos da conservação. Segundo este conceito, a Educação Ambiental estava pautada na conservação da biodiversidade e nos sistemas de vida. Com a Conferência de Estocolmo, realizada em 1972, ampliou-se a sua definição a outros campos do conhecimento. A Conferência Intergovernamental de Tbilisi, ocorrida em 1977, definiu que a Educação Ambiental é um processo de reconhecimento de valores, tendo por objetivo o desenvolvimento das habilidades e modificando as atitudes em relação ao meio, a fim de atender e apreciar as inter-relações entre os seres humanos, suas culturas e seus meios biofísicos, estando também relacionada com a prática das tomadas de decisões que conduzem para a melhoria da qualidade de vida. 
Para Loureiro (2003, p. 40) a Educação Ambiental tem por finalidade "estabelecer processos práticos e reflexivos que levem à consolidação de valores que possam ser entendidos e aceitos como favoráveis à sustentabilidade global, à justiça social e à preservação da vida".

De acordo com Minini (2000), a Educação Ambiental é um processo que consiste em propiciar às pessoas uma compreensão crítica e global do ambiente, para elucidar valores e desenvolver atitudes que lhes permita adotar uma posição consciente e participativa, em relação a questões como a conservação e a utilização adequada dos recursos naturais, a fim de melhorar a qualidade de vida, buscando eliminar a pobreza extrema e o consumismo desenfreado.

Contudo, apesar de sua importância o solo ainda é um tema pouco abordado quer seja no ensino formal em sala de aula, como nas práticas educativas informais desenvolvidas nas escolas, sendo geralmente, desconsiderado e pouco valorado perante o Ensino Básico e diante de outros elementos naturais como a água, o ar, e a vegetação. Nesse contexto, observa-se que o espaço dedicado ao estudo do solo, tanto no Ensino Fundamental como no Médio, é freqüentemente nulo ou relegado a um plano menor, seja nas escolas da área urbana como da rural. Este conteúdo nos materiais didáticos, muitas vezes, não se encontra adequadamente vinculado aos Parâmetros Curriculares Nacionais (PCNs), como sugere Brasil (1998). Além disto, muitas vezes, passa a ser ministrado de forma estanque, sem ser relacionado com a utilidade prática ou cotidiana, causando desinteresse tanto no aluno quanto no professor. Dentre outras, estas razões contribuem para que a população desconheça a importância e características do solo, o que amplia o risco da ação antrópica influenciar nos processos de alteração e degradação desse recurso.

De acordo com Penteado (2010),

"as disciplinas escolares são os recursos didáticos através dos quais os conhecimentos científicos de que a sociedade já dispõe são colocados ao alcance dos alunos. As aulas são o espaço ideal de trabalho com os conhecimentos e onde se desencadeiam experiências e vivencias formadoras de consciências mais vigorosas porque são alimentadas no saber" (PENTEADO, 2010, p. 22).

Nesse contexto, as disciplinas que mais freqüentemente tem incluído em seus programas as questões ambientais são as Ciências Naturais e a Geografia Física. Sabendo-se da importância que o solo possui para o desenvolvimento das atividades humanas este estudo tem por objetivo geral analisar o ensino de solos como uma prática de Educação Ambiental desenvolvida na Escola Municipal de Ensino Fundamental Santo Isidoro - Gaurama/RS.

Como objetivos específicos pretende-se verificar a importância e o enfoque dado, ao tema solo, nos livros didáticos de Geografia do Ensino Fundamental utilizados na referida instituição de ensino; Investigar por meio de entrevistas, como os professores trabalham a Educação Ambiental e como esta encontra-se presente nos livros didáticos utilizados pelos educandos e Analisar as

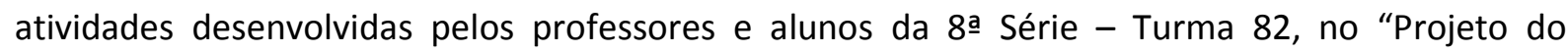
Viveiro" relacionando-as com o ensino e conhecimento do solo e a prática da Educação Ambiental, com vistas a contribuir para um maior conhecimento sobre estas temáticas uma vez que ambas estão presentes, direta ou indiretamente, no nosso dia-a-dia.

\section{METODOLOGIA}

O trabalho vem sendo desenvolvido na Escola Municipal de Ensino Fundamental Santo Isidoro, situada no município de Gaurama/RS. O município de Gaurama localiza-se ao norte do 
estado do Rio Grande do Sul, na região do planalto (Figura 1), entre as coordenadas geográficas

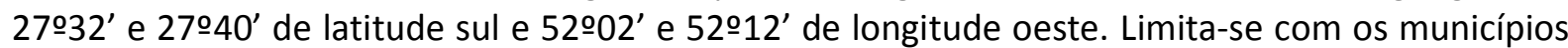
de Três Arroios, Áurea, Viadutos e Erechim. Sua área territorial corresponde a 204,15 Km2 e sua população, conforme IBGE (2010) é de 6.108 habitantes.

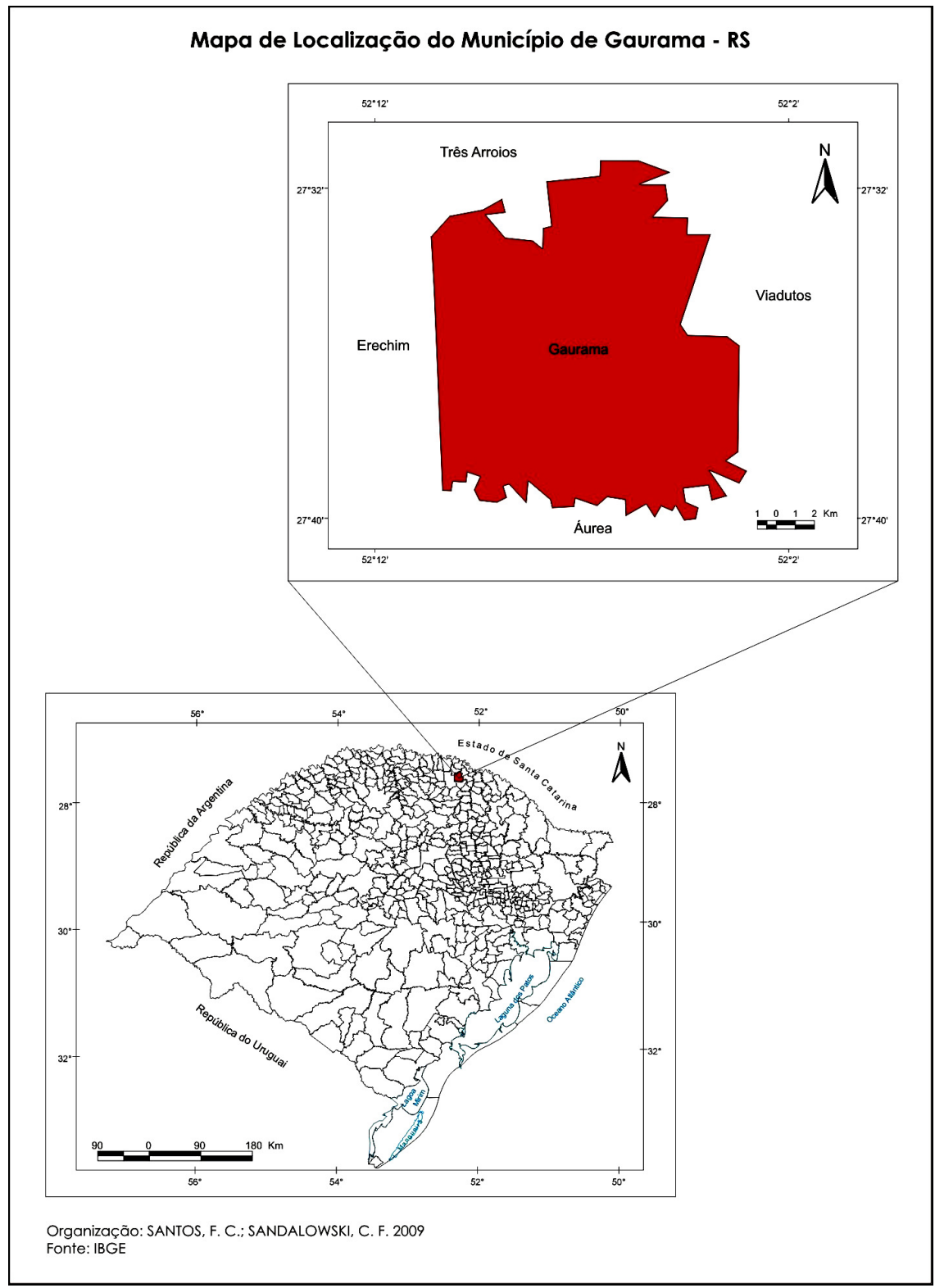

Figura 1 - Localização do município de Gaurama no estado do RS

Esta pesquisa teve início em setembro de 2011, na Escola Municipal de Ensino Fundamental Santo Isidoro. Caracteriza-se por ser uma pesquisa qualitativa, a qual volta sua perspectiva de investigação para a interpretação de dados provenientes de textos e também fenomenológica uma vez que se faz uso da percepção do espaço vivido por meio de observações e vivências das aulas práticas de Técnicas Agrícolas. Inicialmente procurou-se delimitar o tema, para em seguida elaborar os objetivos norteadores deste trabalho. 
$\mathrm{Na}$ fase seguinte iniciou-se o trabalho de gabinete, o qual se concentrou na busca em realizar um levantamento de dados referentes às características gerais do município de Gaurama dando ênfase na Escola Municipal de Ensino Fundamental Santo Isidoro por esta ser a única escola do município a oferecer o Ensino Fundamental completo e estar situada na zona rural.

$\mathrm{Na}$ terceira fase, se organizou a fundamentação teórica referente à temática em questão, buscando ressaltar a relevância do tema e abordar os principais conceitos utilizados no estudo dos solos. A fase seguinte do trabalho constituiu-se no levantamento bibliográfico dos livros didáticos de Geografia, de 5a a 8a Séries utilizados pela Escola Municipal de Ensino Fundamental Santo Isidoro, e na análise do enfoque dado ao tema solo nestes, seguindo o exame de conteúdo previsto por Brasil (1998), de acordo com os conceitos apresentados por este de meio ambiente, educação ambiental e solo.

Posteriormente a análise dos livros didáticos de Geografia, procurou-se investigar por meio de entrevistas informais com os professores de Geografia e Técnicas Agrícolas, como estes profissionais trabalham a Educação Ambiental e como esta se encontra presente nos livros didáticos utilizados pelos educadores e educandos.

Como última etapa analisou-se as atividades desenvolvidas pelos 18 estudantes da Turma 82, da 8a Série (9o Ano), e pelo professor de Técnicas Agricolas no "Projeto do Viveiro" relacionando-as com o ensino e conhecimento do solo e a prática da Educação Ambiental, com vistas a contribuir para um maior conhecimento sobre estas temáticas uma vez que ambas estão presentes, direta ou indiretamente, no nosso dia-a-dia.

\section{RESULTADOS E DISCUSSÃO}

A atividade de pesquisa analisou um total de oito livros didáticos, relativos ao Ensino Fundamental da disciplina de Geografia, utilizados pela Escola Municipal de Ensino Fundamental Santo Isidoro - Gaurama/RS. Buscou-se avaliar a forma como o tema solo é abordado nestes materiais didáticos relativo aos processos de formação, conceitos, tipos, usos e cuidados. Dos oito

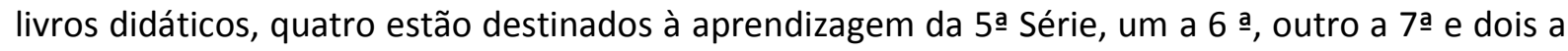
8a Série.

Conforme análise feita nos livros didáticos de 5a a 8a Séries da disciplina de Geografia, foi possível verificar que o tema solo é abordado de forma mais ampla na 5a Série do Ensino Fundamental e que os livros didáticos mais antigos trabalham de forma mais detalhada esse assunto enquanto as edições recentes abordam o tema de forma bem superficial e generalizada. Em relação aos livros didáticos da 6a e 7ạ Séries foi possível verificar que os mesmos trazem a temática solo ainda mais resumida, se compararmos com a série anterior. Contudo, analisando os livros didáticos da 8a Série, que trabalham com os elementos formadores da paisagem natural: clima, relevo, hidrografia e vegetação, foi possível identificar um completo "esquecimento", por parte dos autores, de se trabalhar um dos principais elementos do processo formador da paisagem, o solo.

Nesse sentido, cabe ressalvar que por mais que Brasil (1998) sugira que durante a 8a Série devam ser trabalhados temas como a organização das nações e as inter-relações políticas, econômicas e sociais, o fato é que a temática solo continua sendo ignorada perante os demais recursos naturais abordados nesta fase da aprendizagem.

No caso das entrevistas informais com os professores responsáveis pela disciplina de Geografia e Técnicas Agrícolas, a respeito da forma como estes professores trabalham a Educação Ambiental na escola, foi possível identificar a falta de inter-relação entre as disciplinas, isto é, cada disciplina 
é ministrada como sendo independente e "completa" não possuindo temas de compatibilidade com as demais disciplinas. Esta observação torna claro de como a Educação Ambiental pode vir a contribuir para a inter e multidisciplinaridade de ensino nas escolas.

Conforme Sato (2004),

"todo projeto de investigação ambiental, quando possível, deve buscar uma interação entre as diversas dimensões inerentes à questão ambiental adquirindo, a Educação Ambiental, um caráter interdisciplinar, reforçando a utilização de uma abordagem integradora para a compreensão da problemática ambiental, como resultado da dinâmica do sistema natural e das interações entre os sistemas social e natural" (SATO, 2004, p. 9).

Neste contexto, a Educação Ambiental se insere nas respostas aos problemas ambientais, de desenvolvimento humano a aos do processo educativo justificando, portanto, a razão pela qual a mesma não deve ser considerada uma atividade isolada dos sistemas de investigação e informação ambiental.

Na Proposta Pedagógica desenvolvida pelo Projeto Político Pedagógico (PPP) da escola busca-se, entre outros objetivos,

\begin{abstract}
"proporcionar uma educação inclusiva e de qualidade mediante a participação de toda a comunidade escolar, buscando assim realizar um trabalho voltado à realidade dos alunos e a real necessidade dos mesmos, possibilitando o saber e a cultura permanentes, fundamentados na análise e reflexão voltada para a prática transformadora, para assim, formar alunos responsáveis, críticos e participativos, promovendo-os como cidadãos" (PPP - EMEFSI, 2009, p. 24).
\end{abstract}

Nesse sentido, a escola conta com o Projeto do Viveiro, cuja principal meta está fundamentada na idéia de que, à medida que a humanidade aumenta sua capacidade de intervir na natureza para satisfazer suas necessidades e desejos, surgem e crescem tensões e conflitos quanto ao uso do espaço e de seus recursos. Deste modo, a escola buscando reaproveitar o viveiro de mudas, desde as hortaliças, flores, ervas medicinais e condimentos, ampliou-o e passou a produzir mudas tanto para as necessidades da escola como para o fornecimento de todo o município, por meio de atividades práticas desenvolvidas durante a disciplina de Técnicas Agrícolas.

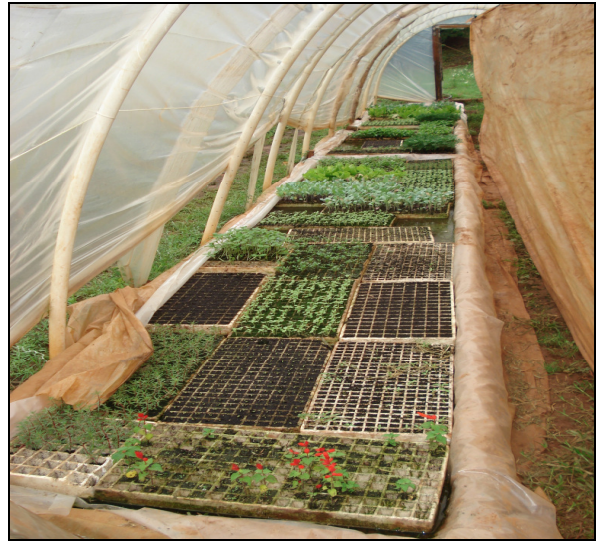

Mudas de flores

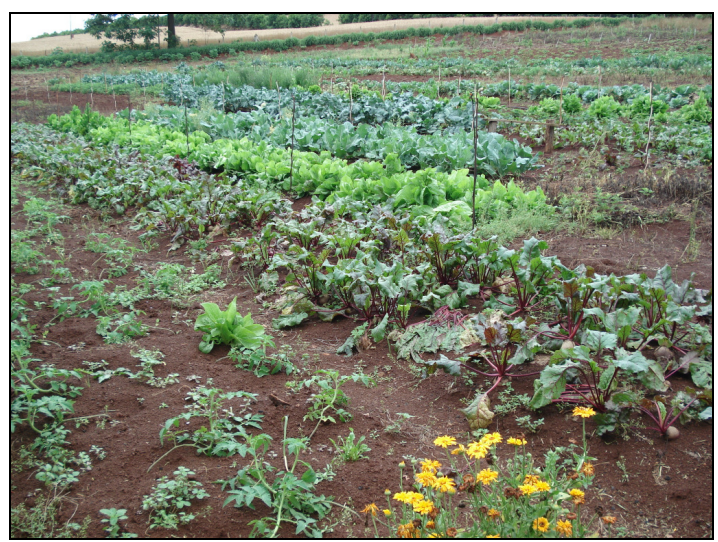

Horticultura 
Estas atividades são desenvolvidas na área do setor agrícola da escola uma vez que a mesma possui um total de $4.090 \mathrm{~m} 2$, na qual os estudantes da $8^{\text {a }}$ Série juntamente com o professor, desenvolvem a partir de um processo educativo que privilegie uma concepção de sustentabilidade na relação sociedade-natureza, o conhecimento básico sobre o solo, como sua gênese, tipos e conservação, promovendo uma abordagem não apenas na simples transmissão de conhecimentos, mas também na experimentação, na investigação, no resgate e na valoração do conhecimento empírico dos próprios educandos, uma vez que estes em sua maioria são provenientes da zona rural do município.

\section{CONCLUSÕES}

A pesquisa realizada buscou investigar como o ensino de solos vem sendo dimensionado no contexto escolar, com o objetivo de verificar se está ou não contribuindo para o desenvolvimento e cognição de novas práticas de Educação Ambiental.

Conforme Brasil (1998), em cada série determinados assuntos/temas devem ser estudados, porém nada impede o professor de trabalhar a temática solo nas séries posteriores ao 6읏 Ano, uma vez que os demais elementos formadores da paisagem continuam sendo abordados nas séries finais do Ensino Fundamental. Verificou-se, contudo, por meio da pesquisa realizada, que a temática solo apesar de não ser abordada em todos os livros didáticos de $5 \underline{a}$ a 8 a Séries do Ensino Fundamental utilizados na Escola Municipal de Ensino Fundamental Santo Isidoro, o conhecimento desse tema ocorre de forma mais contundente nas aulas práticas da disciplina de Técnicas Agrícolas, que tem como "sala de aula" o viveiro da escola. Por meio do "Projeto do Viveiro" os educandos aprendem conhecimentos básicos sobre o solo, como sua gênese, tipos e conservação.

Associando o conhecimento de solos à prática da Educação Ambiental, visa-se a formação de um aluno cidadão, consciente de seus direitos e também deveres para com a sociedade e o meio no qual vive. Nesse contexto, cabe citar Lima (1984 apud GUIMARÃES, 1995, p. 22), em cujo livro Ecologia humana, destaca que "o conteúdo que respalde a relação educação versus meio ambiente deve nascer da reflexão sobre a realidade, que dirige a percepção e gera a prática".

\section{REFERÊNCIAS}

BRASIL. Secretaria de Educação Fundamental. Parâmetros curriculares nacionais: geografia. Brasília: MEC, 1998.

CRUZ, D. Ciências e educação ambiental: o meio ambiente. São Paulo: Ática, 1998.

INSTITUTO BRASILEIRO DE GEOGRAFIA E ESTATÍSTICA. IBGE - Instituto Brasileiro de Geografia e Estatística. Rio de Janeiro, 2011. Disponível em: <http://www.ibge.gov.br>. Acesso em: 04 out. 2011.

GUIMARÃES, M. A dimensão ambiental na educação. Campinas, São Paulo: Papirus, 1995.

LOUREIRO, C.F.B. Trajetória e fundamentos da educação ambiental. São Paulo: Cortez, 2003. 
MININI, N. A formação dos professores em Educação Ambiental. In: Textos sobre capacitação em Educação Ambiental. Oficina Panorama da Educação Ambiental, MEC - SEF - DPEF - Coordenação de Educação Ambiental, Brasília, 2000.

PENTEADO, H. D. Meio ambiente e formação de professores. São Paulo: Cortez, 2010.

SATO, M. Educação Ambiental. São Carlos: Rima, 2004.

SCHNEIDER, R. P. Geografia do Rio Grande do Sul. São Paulo: FTD, 2001.

VESENTINI, J. W.; VLACH, V. Geografia crítica: geografia do mundo subdesenvolvido. São Paulo: Ática, 2002.

VESENTINI, J. W.; VLACH, V. Geografia crítica: o espaço natural e a ação humana. São Paulo: Ática, 2004.

VESENTINI, J. W.; VLACH, V. Geografia crítica: geografia do mundo industrializado. São Paulo: Ática, 2007.

VESENTINI, J. W.; VLACH, V. Geografia crítica: o espaço social e o espaço brasileiro. São Paulo: Ática, 2008.

VESENTINI, J. W.; VLACH, V. Geografia crítica: geografia do mundo industrializado. São Paulo: Ática, 2008.

VESENTINI, J. W.; VLACH, V. Geografia crítica: o espaço natural e a ação humana. São Paulo: Ática, 2009. 